\title{
BRINGING PSYCHOLOGY AND GEOGRAPHY CLOSER
}

\author{
ROBERT M. KITCHIN \\ Department of Geography, University College Swansea, Wales, U.K.
}

\begin{abstract}
Behaviour and Environment: Psychological and Geographical Approaches. Edited by Tommy Gärling and Reginald Golledge. Amsterdam: North Holland, Elsevier Science Publishers B.V., 1993. 481 pp. £89.00. ISBN 0444896980 .

Tommy Gärling is Professor of Psychology at Gothenburg University, Sweden. His main research interest is Environmental Psychology particularly focusing upon behaviour in the natural environment and information processing.
\end{abstract}

Reginald Golledge is Professor of Geography at the University of California, Santa Barbara, U.S.A. He specializes in Analytical Behavioral Geography and has been one of its main proponents for many years, focusing upon models of behaviour, epistemology and philosophical issues.

Robert Kitchin is a Teaching Assistant studying for a doctorate at the University College of Swansea. His research interests include the validity problems of cognitive mapping both at theoretical and methodological level, Behavioral Geography and G.I.S.

Behaviour and Environment aims to examine the potentially fruitful links between geography and psychology in the study of the environmentbehaviour interface. It argues that such links are capable of increasing our scientific knowledge of how human behaviour is interfaced with the molar physical environment, and that such a text is timely as geographers have been citing psychology literature for a number of years but psychologists have only recently acknowledged geographical theory and practice in their work.

It is written by a cross-section of geographers and psychologists and edited by Tommy Gärling (a psychologist) and Reginald Golledge (a geographer) who are both prolific and respected publishers on the links between the environment and behaviour, and who have independently promoted multidisciplinary links in the past (Golledge, 1982; Gärling \& Evans, 1991). Although aimed specifically at those researchers who are interested in the influence of the environment on behaviour, it is also intended as a suitable reference for behavioural geography and environmental psychology courses.

The book evolved out of two principle conferences: the Joint Symposia 1988 International Congresses of Geography and Psychology in Sydney, Australia and the Joint Symposia at the 1990 International Congress of Applied Psychology in Kyoto Japan. Many of the authors also attended the related conferences, Environmental Cognition and Assessment Conference 1988, in Umëa, Sweden and the Association of American Geographers, 1992 discussion on the interface between psychology and geography (see Gärling \& Evans, 1991).

The book contains 17 chapters split into two sections addressing the basic processes of behaviourenvironment interaction and the real world contexts of behaviour-environment interaction. The first section deals specifically with how we cognize, assess and act within the environment at a broad theoretical level, and the second section with how such research is useful in practical and real-world situations. It is organized so that each area of mutual interest is explored first by a geographer, and then by a psychologist, in order to demonstrate how the two disciplines approach the same problem. It must be noted that this book contains no original research, but is a collection of overviews designed to introduce complementary research being carried out in two distinct disciplines. 
Behaviour and Environment, when taken at the level of individual chapters, contains a set of wellwritten and structured reviews of research relevant to psychology and geography, but unfortunately when viewed as whole, one is left with a sense of disappointment and frustration at what could have been. What of its potential and the already explicit links between geography and psychology? The aim of the book was to give state-of-the-art reviews of several different areas of interest on the behaviourenvironment interfaces within which both psychologists and geographers are actively involved, to provide a fuller understanding than each discipline provides by itself, and to tear down the communication barriers between disciplines. Yet it is up to the reader to synthesize the chapters so that potential links are discovered. There are very few crossreferences, and no chapters that outline what could be achieved if the geographical and psychological approaches were integrated together. This is a shame, because with the exception of the opening chapter, the book contains 16 good review papers, and with minor alteration and editing it could have achieved its aims.

However, my major concern is that the book aimed to focus only on geographical and psychological approaches to the environment-behaviour interface. Although psychology and geography are without doubt the two largest contributors to environment-behaviour research there are others, such as architecture and planning, sociology, anthropology, cognitive science, and political science. These, although not quite as productive and as broadly based in their endeavours, have certainly contributed significantly to specific research areas, and yet these were barely mentioned. For a book trying to promote links between disciplines, a comment on the multidisciplinary nature of the study area, would have been appropriate, if only in a short section in the introduction chapter with some type of justification for their wholesale omittance.

The aim of any introduction should be to stimulate, but the introductory chapter, is the weakest of all the chapters, and fails to excite the reader. It does not provide a clear justification for the book, and thus fails to explain why links between the two subjects are important: Why is reading the book going to improve my research? The introduction lacks a detailed summation of the books contents; a resume of the history of each subject; links between the subjects in the past (such as Downs \& Stea, 1973; Moore \& Golledge, 1976; Golledge \& Rayner, 1982; Gärling \& Evans, 1991); and why the book calls for such links. It should have also included a detailed overview of the existing or potential links, with appropriate examples and a detailed summa. tion of existing differences, focusing particularly on philosophical (both environmental psychology and behavioural geography have their own sub. fields: behavioural geography, for example, can be split into humanistic and analytical approaches) and methodological differences (techniques, scale, context). The introductory chapter seemed rushed, briefly explaining the differences between psychological and geography but failing to outline how they could be integrated together to make a better whole. Surely this is fundamental to a book of this type.

The individual chapters, however, make fascinating reading, each providing a broad overview of work being carried out in a particular field. Although not covering all of the relevant research topics, each chapter does manage to summarize a fair proportion of points, and it is certainly a book to refer students to. Key subjects omitted, that concern the environment-behaviour interface include reversing the question by asking how behaviour studies might influence planning of our environment (see Golledge \& Timmermans, 1990; Aitken et al., 1993). One of the largest research areas concerning environment-behaviour interface concerns the development of spatial and environmental cognition, and although learning is briefly covered, its application in the form of educational issues is not (see Spencer et al., 1989; Matthews, 1992). Environment-behaviour research concerning special populations such as the mentally and physically disabled, the elderly and children are also omitted (see Golledge et al., 1979, 1983; Cohen, 1982; Charness, 1985; Matthews, 1992; Golledge, 1993), along with overview concerning specific applications such as wayfinding (see Blades, 1991; Gluck, 1991; Golledge, 1992).

The paired papers, generally, fit neatly together, but unfortunately the first section of the book does not flow, it is a series of independent chapters coupled together, although the second section manages to hang together and is logically ordered. Maybe if chapters 6 and 7 (cognitive processes and cognitive maps) were swapped for 4 and 5 (affective reactions to, and cognitively-orientated appraisals of, environments), a more cohesive text could have been achieved whereby chapters 2 and 3 would have covered spatial cognition, leading into cognitive mapping ( 4 and 5 ), followed by environmental assessment (6, 7, 8 and 9), and finally environmental activity (10 and 11). Another improvement would have been a series of short overview chapters, elaborating on the potential for geographical and 
psychological research integration in each specific field of study. A second important omission is the lack of a concluding chapter designed to summarize the major findings of the reviews and suggesting where integration would be most beneficial.

More specifically, Robert Lloyd's chapter on cognitive processes and cartographic maps, the two chapters concerning environmental hazards (Kasperson \& Dow; Slovic) and the two discussing everyday activities (Hanson \& Hanson; Gärling \& Garvill) are all excellent reviews, which manage to be enjoyable and easily understandable. Robert Lloyd's chapter is a particularly good review of an area of research which previously lacked a comprehensive overview, providing a detailed discussion of the relationship between cognitive processes, cognitive maps and cartographic maps and addressing problems concerning representation, interpretation and learning.

Hirtle's and Heidorn's chapter on the structure of cognitive maps, is probably the weakest of the overview chapters, concentrating only on research concerning hierarchical theories and priming processes. These are by no means the only theories on how we process and store data concerning the every day geographical environment (others include semantic networks, radical image theory, neoassociation, propositional/analogue, duel coding theory, holograms, genetic coding) and a balanced coverage of these would have greatly strengthened their review. Some sections of the other chapters may be tough reading for novices, where it is difficult to simplify complex ideas, but in general the authors have managed to make the book readable and understandable.

The potential links between psychology and geography are numerous, including the mutual development of reliable and experimentally sound methodologies, models, meta-models, theories, and paradigms. The next step in the collaboration should be to develop these potential links in an appropriate way. Cooperation should be promoted between researchers, with the aim of adopting a multidisciplinary stance, fostering an integrative framework within which research strategies, paradigms and theories can be moulded in order to produce a more coherent whole. At present the two subjects share the same interests, many research techniques for similar applications, and yet approach the same subjects using different philosophies and research strategies. If researchers work together in active collaboration and progress towards more comprehensive models and theories, understanding will increase.

Such a strategy will hopefully alleviate the validity problems that currently exist and promote future research. This is starting to happen, with many geographers including descriptions of spatial development theory and cognitive processes in their work, although psychologists are much more unlikely to reference geographical literature. The problems of such an approach need to be explored, but the benefits are obvious. By combining the psychologists small-scale laboratory based methodologies, theories of development, cognitive processes, evaluations and beliefs, with geographers large-scale studies describing actual behaviour, and cognitions of the real world, understanding of spatial cognition, environmental cognition, assessment and activity and their roles in influencing behaviour could be increased, leading to better models of real world behaviour, with benefits for planning and education.

In conclusion, although the book fundamentally fails to show the reader the existing and potential explicit links, between these two disciplines beyond the subjects they share, it does provide a mass of implicit links, through a set of well-written and well-referenced chapters. As a reference book, for related undergraduate courses on behavioural geography or environmental psychology, it would be ideal because it provides a broad overview of how two different subjects approach the same problems and provides an up-to-date guide to the position of research.

Hopefully the book will achieve one of its aims and increase more cross-discipline research but specific advice on how to integrate particular research projects would have been especially useful when one has to consider the validity problems of doing so: Can theories from different philosophical backgrounds be easily integrated without corrupting its validity base? Are methodologies transferable across scales and contexts and what are the consequences to internal and external validity? There are numerous other similar questions, none of which are examined, or even mentioned beyond:

'The other barriers we leave to others to remove' p. 11.

The book's quality is that it contains a set of wellstructured and comprehensive overviews, and in an age when it is increasingly difficult to keep up with all the relevant current research, this book allows quick and easy access to a broad literature. It is an informative and enjoyable read, and would make an ideal book to add to the library of an institution offering courses in environmental psychology or behavioural geography. Perhaps a useful companion book could explore multidisciplinary research rather than just geography and psychology. 


\section{References}

Aitken, S. C., Stutz, F., Prosser, R. \& Chandler, R. (1993). Neighborhood integrity and residential familiarity: using a geographic information system to investigate place identity. Tijdschrift Voor Economische En Social Geografie, 84(1), 2-12.

Blades, M. (1991). Wayfinding theory and research: the need for a new approach. In D. M. Mark \& A. U. Frank, Eds., Cognitive and Linguistic Aspects of Geographic Space. Kluwer Academic Publishers, pp. 137-165.

Charness, N. (Ed.) (1985). Ageing and Human Performance. New York, NY: John Wiley.

Cohen, R. (Ed.) (1982). Children's Conceptions of Spatial Relationships. San Francisco, CA: Jossey-Bass.

Downs, R. M. \& Stea, D. (Eds.) (1973). Image and Environment. Chicago, IL: Aldine.

Gärling, T. \& Evans, G. W. (Eds) (1991). Environment, Cognition and Action-An Integrated Approach. New York, NY: Oxford University Press.

Gluck, M. (1991). Making sense of human wayfinding: review of cognitive and linguistic knowledge for personal navigation with a new research direction. In D. M. Mark \& A. U. Frank, Eds., Cognitive and linguistic aspects of geographic space. Dordrecht, The Netherlands: Kluwer Academic Publishers, pp. 117- 135 .

Golledge, R. G. (1982). Introduction: substantive and methodological aspects of the interface between geography and psychology. In R. G. Golledge \& J. N. Rayner, Eds., Proximity and Preference: Problems in the Multidimensional Analysis of
Large Data Sets. Minneapolis, MN: University of Minnesota Press.

Golledge, R. G. (1992). Place recognition and wayfinding: making sense of space. Geoforum 23(2), 199-214.

Golledge, R. G. (1993). Geography and the disabled: a survey with special reference to vision impaired and blind popula. tions. Transactions of the Institute of British Geographers, 18(1), 63-82.

Golledge, R. G., Parnicky, J. J. \& Rayner, J. N. (1979). An experimental design for assessing the spatial competence of mildly retarded populations. Social Science and Medicine, 13D, 291-295.

Golledge, R. G. \& Rayner, J. N. (1982). Proximity and Preference: Problems in the Multidimensional Analysis of Large Data Sets. Minneapolis, MN: University of Minnesota Press.

Golledge, R. G., Richardson, G. D., Rayner, J. N. \& Parnicky, J. J. (1983). Procedures for defining and analysing cognitive maps of the mildly and mentally retarded. In H. L. Pick \& L. J, Acredolo, Eds., Spatial Orientation: Theory, Research and Application. New York, NY: Plenum Press, pp. 79-104.

Golledge, R. G. \& Timmermans, H. (1990). Applications of behavioral research on spatial problems I: cognition. Progress in Human Geography, 14(1), 57-99.

Matthews, M. H. (1992). Making Sense of Place: Children's Characterisation of Place. Hemel Hempstead: Harvester Wheatsheaf.

Moore, G. T. \& Golledge, R. G. (Eds.) (1976). Environmental Knowing. Stroudsberg, PA: Dowden, Hutchinson and Ross.

Spencer, C., Blades, M. \& Morsley, K. (1989). The Child in the Physical Environment. Chichester: Wiley. 